\title{
Characteristic Patterns of VEGF, Integrins, ER $\alpha$ and HER2 Immunoreactivity Suggest Two Tumor Cell Populations in DMBA-Induced Rat Mammary Tumor
}

\author{
Tomoko Inoue', Toshiyuki Kaidoh ${ }^{1}$, Takao Inoué1 and Shigetsugu Ohgi² \\ ${ }^{1}$ Division of Morphological Analysis, Department of Functional, Morphological and Regulatory Science and ${ }^{2}$ Division of \\ Organ Regeneration Surgery, Department of Surgery, Faculty of Medicine, Tottori University, Nishi-cho 86, Yonago \\ 683-8503, Japan
}

Received May 9, 2005; accepted August 23, 2005

\begin{abstract}
Recent evidence has shown that certain tumors have characteristic cell populations related to tumor progression. Therefore, we investigated tumor cell populations in 7,12-dimethylbenz[a]anthracene (DMBA)-induced rat mammary tumor, an established estrogen-sensitive angiogenic tumor model. The tumors pathologically identified as invasive ductal carcinoma were immunostained using antibodies against the following various molecules: vascular endothelial growth factor (VEGF), integrins, estrogen receptor alpha $(E R \alpha)$, human epidermal growth factor receptor-2 (HER2), p27, and laminin, all of which are known to be related to tumor progression, proliferation and/or prognosis. The basal layer, the outermost layer of tumor lob-

ules facing the basement membrane, was mainly VEGF and integrin $(\alpha 3, \alpha 6$, $\beta 1)$ positive. In contrast, the inner layer, the internal cell layers of the tumor lobules, was mainly ER $\alpha$ and HER2 positive. The p27-positive rate in the inner layer was similarly low to that in the basal layer, suggesting a similar high proliferative potency between these layers. Laminin was positive in the basement membrane surrounding the tumor lobules. These results suggest that the tumor lobules consist of at least two cell populations, the basal and inner layers, with respect to the expression of VEGF, integrins, $E R \alpha$ and HER2; and that these cell populations may have distinct functions in the pathophysiology of this mammary tumor.
\end{abstract}

Key words: cell populations, DMBA-induced rat mammary tumor, immunohistochemistry, integrin, VEGF

\section{Introduction}

The 7,12-dimethylbenz[a]anthracene (DMBA)-induced rat mammary tumor has been frequently used as an experimental rat model of breast cancer [23], because this tumor is an estrogen-sensitive angiogenic tumor [20, 24, 27, 29] and has similar reactivity to treatment for human breast cancer, such as anti-estrogen drugs and ovariectomy [30]. Malignant lesions of this mammary tumor are histopathologically classified as invasive ductal carcinoma, which consists almost completely of homogeneous tumor cells and has very few myoepithelial cells [43]. However, some previous studies have suggested that this tumor consists of functional-

Correspondence to: Tomoko Inoue, Division of Morphological Analysis, Department of Functional, Morphological and Regulatory Science, Faculty of Medicine, Tottori University, Nishi-cho 86, Yonago 6838503, Japan. E-mail: tmk417@grape.med.tottori-u.ac.jp ly different populations of tumor cells. A culture study with an estrogen receptor assay showed that this tumor is composed of two cell populations: a basal cell population that faces the basement membrane and an epithelial cell population located on the luminal side of the tumor lobules, because the former contains one-tenth as many estrogen receptors as the latter [5]. In spite of this suggestion, further studies evaluating cell populations in this tumor have not been sufficiently conducted.

Recent evidence shows that certain tumors, including breast cancers, have characteristic cell populations related to tumor progression $[1,11,39,54]$. Therefore, we examined tumor cell populations in more detail in the DMBA-induced mammary tumor. We performed immunohistochemistry using antibodies against the following various molecules: vascular endothelial growth factor (VEGF), integrins, estrogen receptor alpha $(\mathrm{ER} \alpha)$, human epidermal growth factor receptor-2 (HER2), p27, and laminin, which have im- 
portant functions in the pathophysiology of breast cancer. VEGF, a major tumor angiogenic factor, was detected in this tumor using RT-PCR and immunohistochemistry [20, 35]. The immunohistochemistry using paraffin-embedded tumor tissues and a microwave antigen retrieval method showed uniform positive staining of VEGF in the tumor parenchyma. However, the present immunohistochemistry, using freshly frozen tumor tissues, showed a different staining pattern of VEGF in the tumor parenchyma, suggesting the existence of certain tumor cell populations. Integrins are characterized as a family of cell surface receptors for extracellular matrix proteins such as laminin [50]. $\alpha 3, \alpha 6$, $\beta 1, \beta 4$ integrin subunits examined in this study are expressed in various epithelial cells and are concerned with tumor invasion or metastasis [8, 19, 33, 49]. Northern and Western blotting analysis suggested that mRNA and proteins of $\alpha 6, \beta 1$ and $\beta 4$ integrins were heterogeneously expressed in DMBA-induced mammary tumors and a cell line derived from this tumor [22]. However, the distribution of these integrins in this tumor tissue is obscure. HER2-overexpressive mammary tumors are known to have a poor prognosis. Although biological therapy using a monoclonal antibody for HER2 protein (trastuzumab) is effective for HER2-positive tumors [36], the interaction between HER2 positivity and the response to endocrine therapy in ER $\alpha$ positive breast cancer is controversial [17]. Since endocrine therapies are effective in the DMBA-induced mammary tumor, we examined the distribution of HER2 and compared it to that of ER $\alpha$ to speculate on the interaction between these molecules. p27 expression indicates the arrest of cell proliferation because p27 stops the progression of the first gap phase (G1-phase) to the DNA synthesis phase (S-phase) in the cell cycle [45]. Therefore, we compared the proliferative potency between different tumor populations using p27 immunohistochemistry.

The aim of this study was to re-evaluate tumor cell populations with regard to the various molecules with pathophysiological importance in the mammary tumor. We will discuss the function of these cell populations in this tumor, and the causes underlying the acquisition of properties in these cell populations.

\section{Materials and Methods}

\section{Animal model}

Virgin female Sprague-Dawley rats (SLC Co., Hamamatsu, Japan), 8 weeks old and weighing about $250 \mathrm{~g}$, were fed with $8 \mathrm{mg}$ DMBA (Sigma Chemical Co., St. Louis, MO, USA) per $100 \mathrm{~g}$ body weight (20 mg per rat) by single administration [23, 43]. Some previous studies have used mammary tumors induced by lower doses of DMBA ( 5 to $10 \mathrm{mg}$ per rat). However, this study employed the original method [23] because it allowed us to obtain rapidly growing mammary tumors and thereby establish the histological classification of this tumor [43]. DMBA was dissolved in sesame oil and administered through a gastric tube. All the animals were maintained in an environmentally control- led clean air room with a $12 \mathrm{hr}$-light/12 hr-dark cycle. All animals were transferred to clean cages with fresh bedding twice a week. Basal diet, CE-2 (CREA JAPAN, Inc., Tokyo, Japan), in feeders and tap water via automatic stainless steel nozzles were freely available throughout the study. The rats were palpated weekly for three months to detect the presence of mammary tumors. Thirty-seven mammary tumors from ten rats, measuring 5-20 $\mathrm{mm}$ in diameter, were removed from the cervico-thoracic glands and the abdominalinguinal glands. Of these tumors, we used ten tumors from 10 to $15 \mathrm{~mm}$ in diameter without a central necrosis because the present immunohistochemical comparison requires the examination of malignant tumors with similar rapid growth rates and intrinsic conditions. This study was carried out according to the Guidelines for the Care and Use of Laboratory Animals at Tottori Universiry.

\section{Specimen preparations for light microscopy}

We consistently used fresh frozen tumor tissues for hematoxylin and eosin (H\&E) staining and immunohistochemistry because formalin-fixed, paraffin-embedded tissues sometimes required antigen retrieval techniques such as microwave heating, or proteolytic pretreatments that influence the immunoreactivity of antibodies and possibly cause false-positive immunostaining. The removed mammary tumors were embedded in the medium (Tissue-Tek OCT Compound; Sakura Fine Technical, Tokyo, Japan) and immediately frozen in dry ice-ethanol. Frozen sections fixed in $4 \%$ paraformaldehyde solution in $0.1 \mathrm{M}$ phosphate buffer $(\mathrm{pH} 7.4)$ were stained with hematoxylin and eosin. The tumor tissues were histopathologically classified according to the previous study [43].

For immunohistochemistry, we used ten tumors that were from 10 to $15 \mathrm{~mm}$ in diameter. Frozen sections of tumor tissues were cut at $8 \mu \mathrm{m}$ thickness with a cryostat, mounted on silane-coating slides and air dried for $30 \mathrm{~min}$. They were fixed either in Zamboni fixative for $10 \mathrm{~min}$ at room temperature for immunohistochemistry of VEGF, $\mathrm{ER} \alpha, \mathrm{HER} 2$ and $\mathrm{p} 27$, or in methanol-acetone for $10 \mathrm{~min}$ at $-20^{\circ} \mathrm{C}$ for that of $\alpha 3, \alpha 6, \beta 1, \beta 4$ integrins and laminin. After washing in phosphate-buffered saline (PBS), the sections were treated with $0.5 \%$ Triton-X100 in PBS for 30 min, and blocked with $1 \%$ bovine serum albumin in PBS containing $5 \%$ normal goat serum for $30 \mathrm{~min}$ at $4{ }^{\circ} \mathrm{C}$ to suppress non-specific binding of subsequent reagents. The sections were incubated with the primary antibodies (listed in Table 1), intermittently irradiated with microwaves at $150 \mathrm{~W}$ for $10 \mathrm{~min}$ with the temperature control set to lower than $37^{\circ} \mathrm{C}$ to facilitate antibody permeation into the tissue sections, and left for $2 \mathrm{hr}$ at room temperature. After washing 3 times with PBS, the sections were incubated in Envision+, goat anti-rabbit immunoglobulins conjugated with peroxidase-labelled dextran polymer (DAKO, Carpenteria, CA, USA), and processed in the microwave oven in the same conditions and left for $2 \mathrm{hr}$ at room temperature. After PBS washing, sections were stained with 3,3'-diaminobenzidine tetrahydrochloride (Dojindo Laboratories, Kumamoto, 
Table 1. Primary antibodies used for immunohistochemistry

\begin{tabular}{llll}
\hline \multicolumn{1}{c}{ Antibody } & Code No. & Dilution & \multicolumn{1}{c}{ Origin } \\
\hline Anti-VEGF & A-20 & $1: 200$ & Santa Cruz Biotechnology Inc., Santa Cruz, CA \\
Anti- $\alpha$ 3 integrin & AB1920 & $1: 50$ & Chemicon, Temecula, CA \\
Anti- $\alpha$ integrin & H-87 & $1: 50$ & Santa Cruz Biotechnology Inc. \\
Anti- $\beta 1$ integrin & AB1952 & $1: 50$ & Chemicon \\
Anti- $\beta 4$ integrin & AB1922 & $1: 50$ & Chemicon \\
Anti-ER $\alpha$ & MC20 & $1: 200$ & Santa Cruz Biotechnology Inc. \\
Anti-HER2 & A0485 & $1: 100$ & DAKO, Carpenteria, CA \\
Anti-p27 & C-19 & $1: 200$ & Santa Cruz Biotechnology Inc. \\
Anti-laminin & RB-082-A0 & $1: 800$ & Lab Vision, Fremont, CA \\
\hline
\end{tabular}

Japan) for $10 \mathrm{~min}$. The sections were counterstained for 10 min with methyl green, dehydrated through increasing concentrations of ethanol, and finally coverslipped. Negative controls were obtained by omitting the primary antibody and replacing it with normal rabbit $\mathrm{IgG}$.

\section{Quantitation of immunohistochemistry}

Several lobules with a clear outline were chosen from randomly selected fields of each tumor tissue. The immunopositive tumor cells for VEGF, integrins, ER $\alpha$, HER2 and p27 with a clear nucleus were counted in the basal and inner layers separately, and at least 1000 tumor cells were counted for each antigen. Labeling indices for these molecules were calculated as percentage values based on the total number of cells examined in the basal or inner layers. Statistical significance was evaluated using Fisher's exact test. A p-value less than 0.05 denoted the presence of significant difference.

\section{Specimen preparations for transmission electron microscopy}

The rats with mammary tumors were fixed by cardiac perfusion of $2 \%$ formaldehyde and $2.5 \%$ glutaraldehyde solution in $0.1 \mathrm{M}$ phosphate buffer $(\mathrm{PB}, \mathrm{pH} 7.4)$. The lactating rats were also fixed in the same manner. The tumor tissues and lactating mammary glands were cut into small pieces and immersed in the same fixative for $2 \mathrm{hr}$, postfixed in $1 \%$ osmium tetroxide for $1 \mathrm{hr}$, and block-stained with $2 \%$ uranyl acetate for $2 \mathrm{hr}$. They were then dehydrated in graded ethanol and embedded in Epon. Thin sections of the mammary tumors and mammary glands were stained with uranyl acetate and lead citrate followed by examination with a Hitachi H-7000 transmission electron microscope (Hitachi High-Technologies Corp., Tokyo, Japan) at $75 \mathrm{kV}$.

\section{Results}

All ten DMBA-induced mammary tumors used were pathologically classified as invasive ductal carcinoma, and the epithelium of the tumor lobules mainly consisted of two to several layers (Fig. 1). Cuboidal epithelial cells sometimes lined the basal or luminal borders of the tumor lobules. The cuboidal epithelial cells that lined the basal layer appeared to not be typical myoepithelial cells. We performed immunohistochemistry to examine tumor cell populations in these mammary tumors. To describe the following results, we named the outermost layer of tumor lobules that faced the basement membrane the basal layer, and the other internal cell layers of the tumor lobules the inner layer. The immunoreactivity of VEGF and integrins $(\alpha 3, \alpha 6, \beta 1)$ was commonly detected in the cytoplasm of the tumor cells mainly in the basal layer (Fig. 2a-d). The staining intensity was different between these antigens, that is, VEGF and integrin $\alpha 6$ were strongly positive, whereas integrin $\alpha 3$ and integrin $\beta 1$ were moderately positive. In contrast, ER $\alpha$ immunoreactivity was detected in the nucleus of the tumor cells mainly in the inner layer. Tumor cells in the basal layer were almost all ER $\alpha$ negative (Fig. 2e). HER2 immunostaining showed membranous reactivity of the tumor cells mainly in the inner layer (Fig. 2f). p27 was detected in the nucleus of the tumor cells both in the basal and inner layers (Fig. 2g). The p27 immunoreactive tumor cells were scattered in the parenchyma and the differences in the p27 immunoreactivity between these layers were not very distinct.

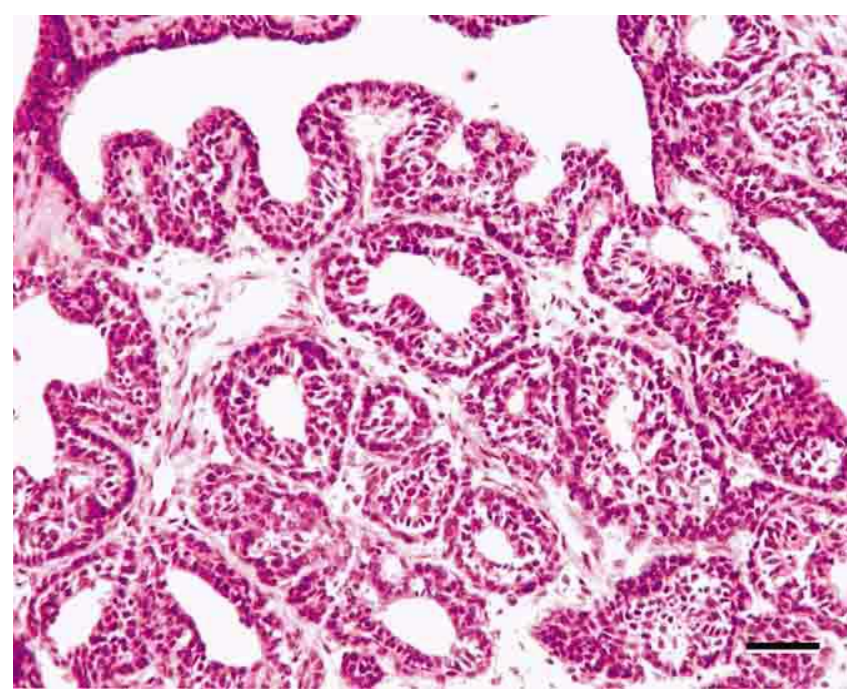

Fig. 1. Hematoxylin and eosin staining of DMBA-induced rat mammary tumor. The histopathological form of this tumor is invasive ductal carcinoma. The epithelium of the tumor lobules consists of two to several layers. Cuboidal epithelial cells often lined the basal or luminal borders. Bar $=200 \mu \mathrm{m}$. 

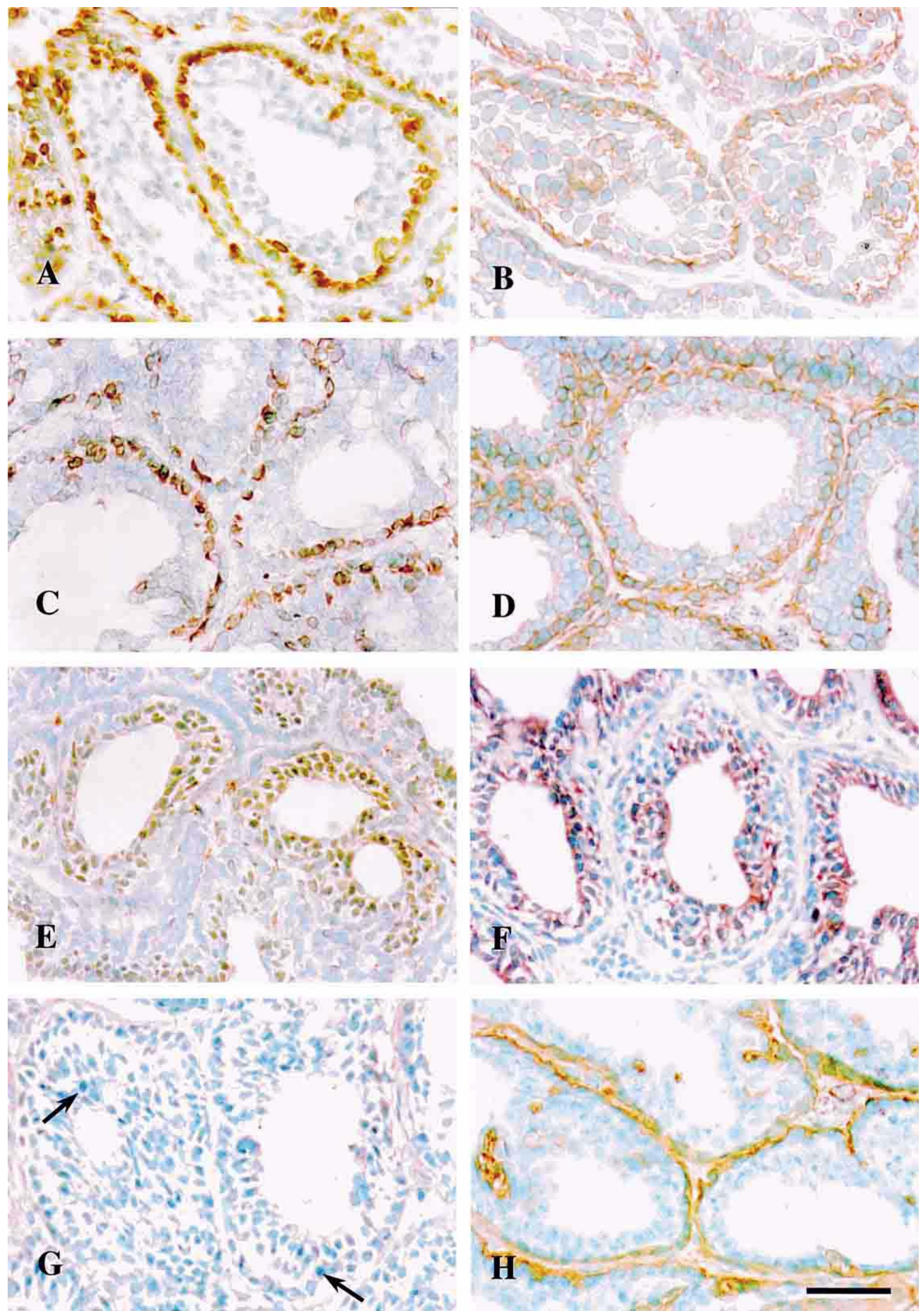

Fig. 2. Immunostaining of VEGF, integrins $(\alpha 3, \alpha 6, \beta 1)$, ER $\alpha$, HER2, p27 and laminin in DMBA-induced rat mammary tumors. A: VEGF, B: $\alpha 3$ integrin, C: $\alpha 6$ integrin, D: $\beta 1$ integrin, E: ER $\alpha, \mathbf{F}:$ HER2, G: p27, H: laminin. Tumor cells in the basal layer show a positive reaction of VEGF, integrins $(\alpha 3, \alpha 6, \beta 1)$ as a brown precipitate in their cytoplasm. Tumor cells in the inner layer show a positive reaction of ER $\alpha$ and HER2 as a brown precipitate. ER $\alpha$ is positive in the nucleus of the tumor cells. VEGF and $\alpha 6$ integrin are strongly positive, whereas $\alpha 3$ and $\beta 1$ integrins are moderately positive. p27 positive nuclei (arrows) are scattered both in the basal and inner layers. Laminin immunoreactivity is positive in the basement membrane surrounding the tumor lobules. Bar $=200 \mu \mathrm{m}$. 
Table 2. Intensity and distribution of VEGF, integrins ( $\alpha 3, \alpha 6, \beta 1$, $\beta 4), E R \alpha, H E R 2, p 27$ and laminin immunoreactivity in DMBA-induced rat mammary tumors

\begin{tabular}{lccrc}
\hline & \multicolumn{2}{c}{ tumor cells } & & stroma \\
\cline { 2 - 3 } \cline { 5 - 5 } & basal layer & inner layer & & basement membrane \\
\hline VEGF & ++ & - & & - \\
$\alpha 3$ integrin & + & - & & - \\
$\alpha 6$ integrin & ++ & - & & - \\
$\beta 1$ integrin & + & - & & - \\
$\beta 4$ integrin & \pm & \pm & & - \\
ER $\alpha$ & - & + & & - \\
HER2 & - & + & & - \\
p27 & + & + & & - \\
laminin & - & - & & + \\
\hline
\end{tabular}

++ : strong positive, + : moderate positive, \pm : weak positive, - : negative.

The immunostaining of integrin $\beta 4$ showed weak cytoplasmic staining in the tumor cells (micrographs not shown). Laminin immunoreactivity was positive in the basement membrane surrounding the tumor lobules (Fig. 2h). The immunohistochemical staining patterns of this mammary tumor are summarized in Table 2. These results suggest that the tumor lobules in this mammary tumor consist of at least two cell populations, the basal and inner layers, with respect to the expression of VEGF, integrins $(\alpha 3, \alpha 6, \beta 1)$, ER $\alpha$ and HER2.

Quantitative comparisons were made of the positive rates of VEGF, integrins, ER $\alpha$, HER2 and p27 between the tumor cells in the basal layer and those in the inner layer (Fig. 3). The positive rates of VEGF and integrins were significantly higher in the basal layer than in the inner layer. In contrast, the positive rates of ER $\alpha$ and HER2 were significantly higher in the inner layer than in the basal layer. The positive rate of p27 in the inner layer was similarly low to that in the basal layer. The characteristics of tumor cell populations shown by immunohistochemistry could be confirmed by these quantitative comparisons.

In benign mammary tumors as well as mammary glands, myoepithelial cells surrounding tumor lobules can be seen. To confirm whether or not the myoepithelial cells consist of the cell population in the basal layer of this mammary tumor, we compared the ultrastructures of lactating mammary glands and tumor tissues. In the lactating mammary glands, the acini consisted of milk-producing epithelial cells and myoepithelial cells (Fig. 4a). The myoepithelial cells have numerous myofilaments and dense bodies in their cytoplasm (Fig. 4b). In DMBA-induced mammary tumors, tumor lobules consisted of tumor cells containing a large nucleus sometimes with prominent nucleoli (Fig. 4c). Tumor cells in the inner layer contained many mitochondria and flattened rER, but those in the basal layer contained a small number of mitochondria and rER with product accumulation in their lumen (Fig. 4d). Myofilaments, which are characteristics of the myoepithelial cells, were not seen in the tumor cells of either inner or basal layers. Although the ultrastructural phenotype of the tumor cells in the basal layer were slightly different from those in the inner layer, the tumor cells in the basal layer appeared to not have a myoepithelial phenotype.

\section{Discussion}

This immunohistochemical study demonstrated the possibility that the lobules of DMBA-induced rat mammary

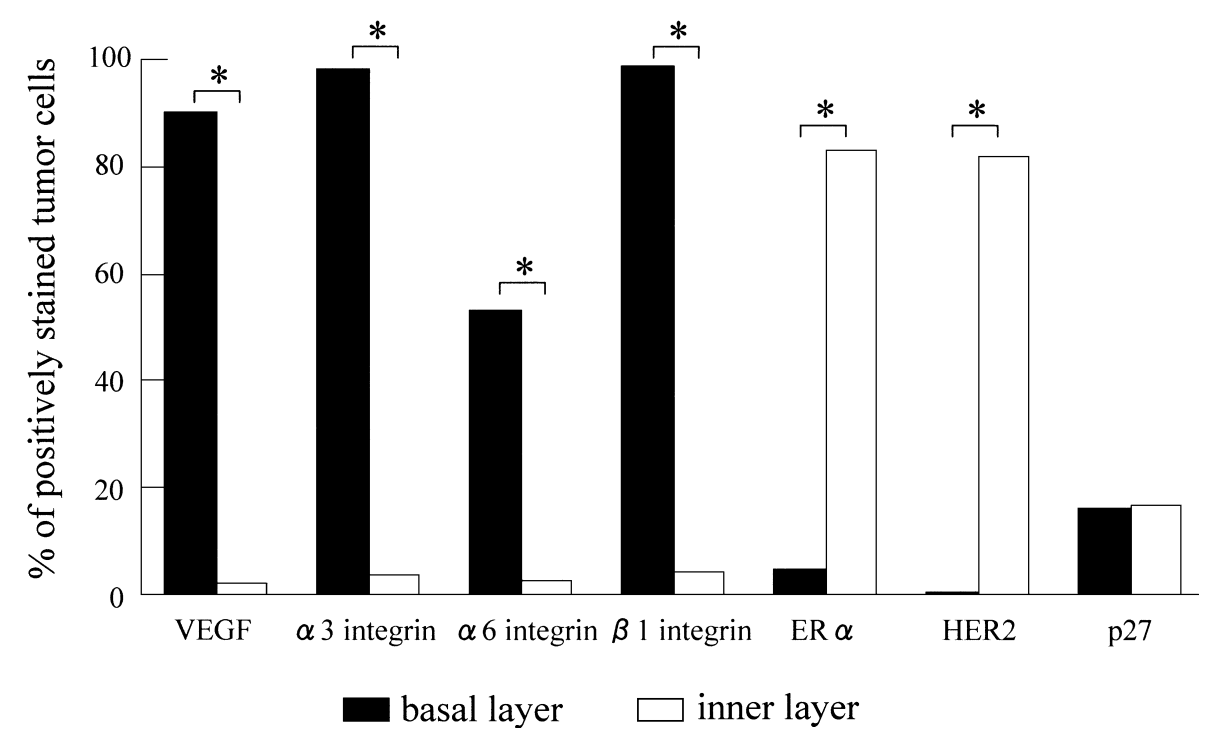

Fig. 3. Comparison of VEGF, integrins, ER $\alpha$, HER2 and p27-positive rates between the tumor cell populations in the inner layer and those in the basal layer. The positive rates of VEGF and integrins are significantly higher in the basal layer than in the inner layer $(* \mathrm{p}<0.001)$. The positive rates of ER $\alpha$ and HER2 are significantly higher in the inner layers than in the basal layer $\left({ }^{*} \mathrm{p}<0.001\right)$. The positive rates of p27 are similar between the two layers. 

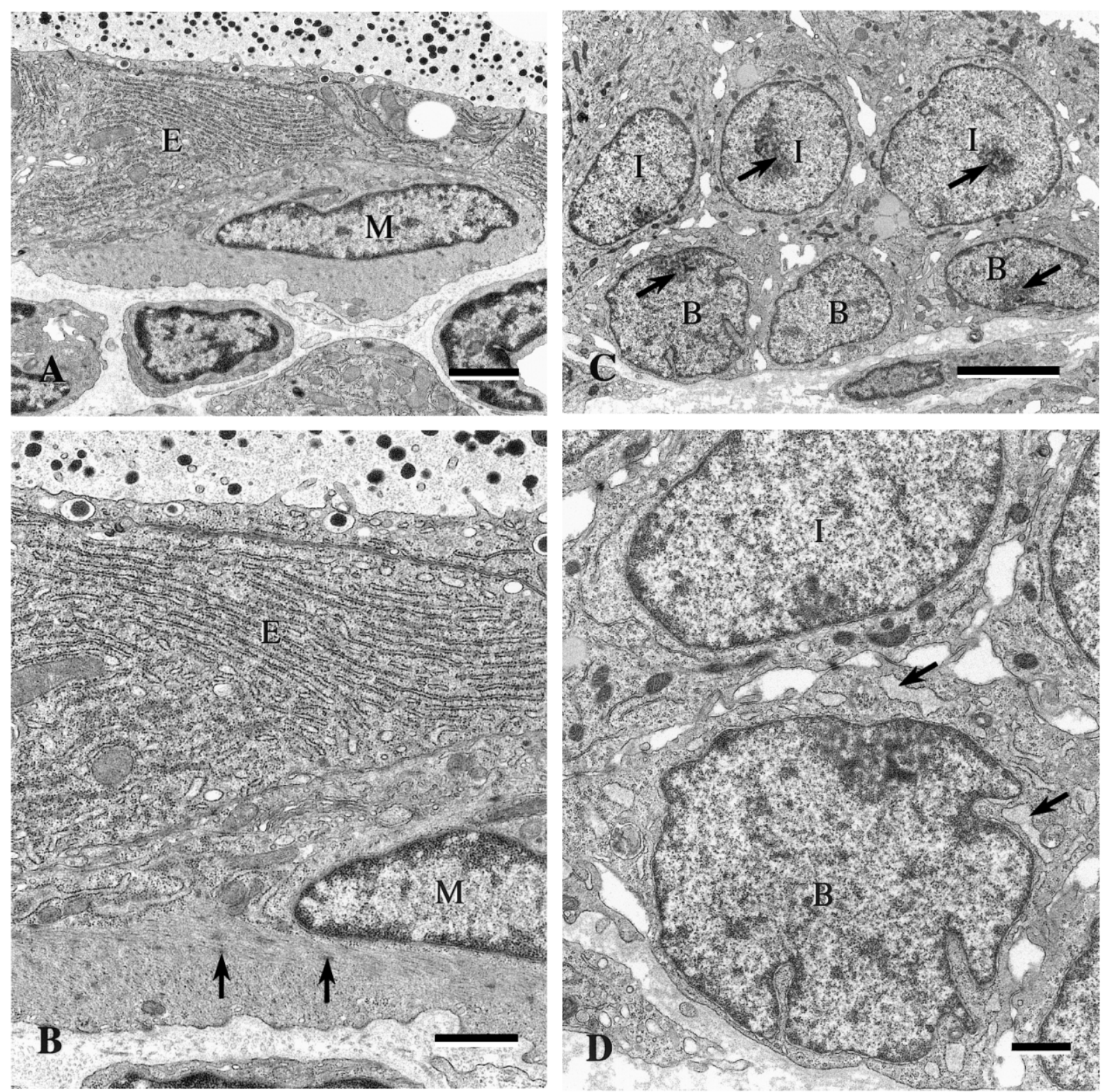

Fig. 4. Electron micrographs showing the lactating mammary glands and DMBA-induced mammary tumors. A: In the lactating mammary glands, the acini consist of epithelial cells (E) and myoepithelial cells (M). B: A higher magnification of A shows that the epithelial cells (E) contain well-developed rER and secrete milk proteins into the lumen. The myoepithelial cells (M) have numerous myofilaments and dense bodies (arrows) in their cytoplasm. C: In DMBA-induced mammary tumors, the tumor lobule consists of tumor cells containing a large nucleus sometimes with prominent nucleoli (arrows). D: A higher magnification of $\mathbf{C}$ shows that the tumor cells in the inner layer (I) contain many mitochondria and flattened rER, but those in the basal layer (B) contain small numbers of mitochondria and rER with product accumulation in their lumen (arrows). Myofilaments are not seen in the tumor cells of either the inner or basal layer. Bars=2 $\mu \mathrm{m}(\mathbf{A}), 1 \mu \mathrm{m}(\mathbf{B}, \mathbf{D})$, $5 \mu \mathrm{m}(\mathbf{C})$,

tumor consisted of two cell populations: the basal layer that was mainly VEGF and integrin $(\alpha 3, \alpha 6, \beta 1)$ positive, and $\mathrm{ER} \alpha$ and HER2 negative, and inversely the inner layer that was mainly VEGF and integrins $(\alpha 3, \alpha 6, \beta 1)$ negative, and ER $\alpha$ and HER2 positive. The tumor cell populations in each layer probably have distinct functions, in tumor progression, proliferation and/or prognosis according to the expression of specific molecules.
The question we must answer first is whether the tumor cells in the basal layer are malignant epithelial cells or cells with a myoepithelial phenotype. The mammary tumors used showed rapid growth suggesting malignancy; actually they enlarged in size to $10-15 \mathrm{~mm}$ in diameter within only three months after DMBA administration. According to the histologic classification of tumors of the rat mammary gland, the tumor tissues examined were invasive ductal carcinoma 
[43]. Typical myoepithelial cells could not be found in the basal layer or around the tumor lobules using light and transmission electron microscopy. Lack of stellate or spindle shaped myoepithelial cells has been also confirmed by scanning electron microscopy [53]. A DMBA carcinogenesis study suggested that the target cells of DMBA are an intermediate type of epithelial cells, but not myoepithelial cells [44]. In addition, as far as we know, VEGF expression has not been reported in the myoepithelial cells of mammary glands [37]. On the other hand, a previous immunohistochemical study using mammary tumors induced by a lower dose of DMBA showed myosin immunopositive myoepithelial cells occasionally around tumor lobules [15]. However, these cells appeared not to correspond to the tumor cell population of the basal layer indicated in the present study. Some other studies have suggested the presence of myoepithelial-like cells in DMBA-induced mammary tumors or their cell lines. However, bundles of myofilaments, an ultrastructural characteristic of myoepithelial cells, have not been demonstrated in the myoepithelial-like cells $[5,25,52]$. Based on the present and previous studies, we concluded that the tumor cells in the basal layer are malignant epithelial cells, rather than cells with a myoepithelial phenotype.

The primary characteristic of the basal layer was its strong positive expression of VEGF. VEGF secretion from the tumor cells adjacent to the stromal tissue is thought to be effective in producing angiogenesis, which supplies nutrition and oxygen to the tumor parenchyma. VEGF expression is regulated by a number of factors. Some previous studies reported that VEGF expression is regulated by estrogen in DMBA-induced mammary tumor and breast cancer cell lines $[7,35,42]$. However, this regulatory mechanism seems not to fit into the results of present immunohistochemical study, as well as previous estrogen receptor studies, because $\operatorname{ER} \alpha$ was negative or very low in the basal layer [5]. It is therefore conceivable that VEGF is regulated by factors other than estrogen in this tumor. Recent studies have suggested that VEGF is up-regulated by hypoxia [51], $\alpha 6 \beta 1$ and $\alpha 6 \beta 4$ integrins [13, 14], TGF $\beta$ [10], and p53 mutation [18]. We show here that in the basal layer, $\alpha 6$ and $\beta 1$ integrins were positive and this layer was surrounded by laminin, which is a component of the basement membrane and a ligand of $\alpha 6 \beta 1$ integrin. Therefore, the adhesion of tumor cells to the basement membrane via $\alpha 6$ and $\beta 1$ integrins possibly up-regulates VEGF expression, which may induce angiogenesis in the tumor stroma.

Positive immunoreactivity of $\alpha 3$ integrin, as well as $\alpha 6$ and $\beta 1$ integrins, mainly in the basal layer suggests that the tumor cell population in this layer may express $\alpha 3 \beta 1$ and $\alpha 6 \beta 1$ integrins as the functional dimers. These integrin molecules are important laminin receptors responsible for invasion and metastasis in mammary carcinoma cells [33, 34]. In addition to this, DMBA-induced mammary tumors uniformly express matrix metalloprotease-9 (MMP-9), which is implicated in tumor invasion and metastasis [4]. In reality, despite the expression of these integrins and MMP-9 at least in the basal layer, the DMBA-induced mammary tumor is invasive but non-metastasizing. These molecules probably facilitate invasion but may not be satisfactory for metastasis in this tumor. The DMBA-induced mammary tumor may lack some essential abilities for metastasis other than integrins and MMP-9 because the metastatic process requires the completion of several selective steps. Although $\alpha 3 \beta 1$ and $\alpha 6 \beta 1$ integrins are important molecules for metastasis, it should be mentioned that the expression of these integrin molecules is not always associated with the metastatic phenotype of mammary tumor cells.

In the present study, the primary characteristic of the inner layer was the positive expression of ER $\alpha$. This is consistent with the results from the estrogen receptor assay [5]. Recently, two immunohistochemical studies examined the $\mathrm{ER} \alpha$ expression in DMBA-induced mammary tumors that were induced by lower doses of DMBA in Sprague-Dawley or Noble rats $[12,28]$. These studies showed the weak to moderate nuclear immunostaining of ER $\alpha$, but did not show any characteristic patterns of ER $\alpha$ immunostaining, as shown in this study. One possible reason why DMBAinduced mammary tumors show different patterns of ER $\alpha$ immunostaining may be because of differences in the doses of carcinogen or strains of rats between the studies.

The secondary characteristics of the inner layer were the expression of HER2, as well as ER $\alpha$. Although a previous study showed that mammary adenocarcinoma induced by a lower dose of DMBA expressed mRNA of HER2 [32], in the mammary tumor induced by a higher dose of DMBA as in this study, the expression and immunohistochemical localization of HER 2 were obscure. The interaction between HER2 positivity and the response to endocrine therapy in ER $\alpha$ positive breast cancer has thus been disputed, and previous studies have repeatedly indicated an adverse interaction between HER2 positivity and endocrine therapy in ER $\alpha$ positive breast cancer $[3,9,16,47,48]$. However, a recent study suggested that HER2 overexpression does not adversely, and may even favorably, influence the response to adjuvant ovariectomy and treatment of the anti-estrogen drug tamoxifen in patients with ER $\alpha$-positive breast cancer [31]. In DMBA-induced mammary tumors, these treatments are known to be effective $[30,38]$. Therefore, the biological interaction between ER $\alpha$ and HER2 during these treatments in this tumor is presumably similar to that in human breast cancer reported by the latter study [31]. The DMBA-induced mammary tumor may be a useful animal model to examine the role of HER2 in endocrine therapy.

In this tumor, why does the tumor cell population in the basal layer refuse to express ER $\alpha$ and HER2? Flow cytometry of human breast cancer cells showed an inverse relationship between ER $\alpha$ and $\alpha 6$ integrin expression and suggested that the integrin levels may be hormonally regulated [34]. This inverse relationship was more distinctly observed in the DMBA-induced mammary tumor. In addition to the previous suggestion, it is also conceivable as an alternative explanation that ER $\alpha$ expression may be down-regulated by $\alpha 6$ integrin in the basal layer. However, evidence supporting 
this explanation has yet to be reported. On the other hand, a recent study in breast cancer cells showed that $\alpha 6 \beta 1$ integrin inhibits HER2 signals by inducing proteasome-dependent proteolytic cleavage of the HER2 cytoplasmic domain [46]. Since the antibody that we used labels the cytoplasmic domain of the HER2 molecule, this proteolytic cleavage may cause a low immunoreaction for HER2 in the basal layer. $\alpha 6$ integrin, which is fundamentally a cell adhesion molecule, may cause negative or low immunoreactivity of $\mathrm{ER} \alpha$ and HER2 in the tumor cell population of the basal layer. However, further studies are required to answer that question.

The p27-positive rate in the inner layer was similarly low to that in the basal layer. This indicates that tumor cell populations in both layers have a similar high proliferative potency. If estrogen simply increases the growth of estrogen-sensitive mammary tumor cells via ER $\alpha$ [2], the distribution of ER $\alpha$ in the tumor lobules must be homogeneous. The reason why the low level of ER $\alpha$ expression in the basal layer did not cause low proliferative potency may be that indirect mechanisms via growth factors, such as TGF $\beta$ and IGF $[6,40,41]$, regulate the proliferation of tumor cells in addition to the direct mechanism of estrogen to tumor cells $[21,26]$.

The characteristics of breast cancer cells have been examined at the molecular and genetic level, and the expression of various proteins has been recognized in these cells. Although various proteins present heterogeneously in tumor tissues, it has not been fully examined how specific cell populations expressing specific proteins are distributed in tumor tissues. The present immunohistochemical study thus provides important evidence that two cell populations exist, with regard to the VEGF, integrins, ER $\alpha$ and HER2 expression, which are known to be related to tumor pathophysiology. The tumor cell population in the basal layer showing immunoreactivity of VEGF and integrins $(\alpha 3, \alpha 6, \beta 1)$ may be predominantly related to angiogenesis and invasion, and $\alpha 6$ or $\alpha 6 \beta 1$ integrin may play some roles to regulate the expression of certain functional molecules, such as VEGF, ER $\alpha$ or HER2. This mammary tumor is probably a useful model to further examine the following topics: the characteristics of the tumor cell populations, the functions of VEGF, integrins, ER $\alpha$ and HER2, and the relationships between these molecules in the mammary tumor.

\section{References}

1. Al-Hajj, M., Wicha, M. S., Benito-Hernandez, A., Morrison, S. J. and Clarke, M. F. (2003) Prospective identification of tumorigenic breast cancer cells. Proc. Natl. Acad. Sci. U S A 100; 39833988.

2. Ali, S. and Coombes, R. C. (2000) Estrogen receptor alpha in human breast cancer: occurrence and significance. J. Mammary Gland Biol. Neoplasia 5; 271-281.

3. Andrulis, I. L., Bull, S. B., Blackstein, M. E., Sutherland, D., Mak, C., Sidlofsky, S., Pritzker, K. P., Hartwick, R. W., Hanna, W., Lickley, L., Wilkinson, R., Qizilbash, A., Ambus, U., Lipa, M., Weizel, H., Katz, A., Baida, M., Mariz, S., Stoik, G.,
Dacamara, P., Strongitharm, D., Geddie, W. and McCready, D. (1998) neu/erbB-2 amplification identifies a poor-prognosis group of women with node-negative breast cancer. Toronto Breast Cancer Study Group. J. Clin. Oncol. 16; 1340-1349.

4. Banerjee, S., Bueso-Ramos, C. and Aggarwal, B. B. (2002) Suppression of 7,12-dimethylbenz(a)anthracene-induced mammary carcinogenesis in rats by resveratrol: role of nuclear factorkappaB, cyclooxygenase 2, and matrix metalloprotease 9. Cancer Res. 62; 4945-4954.

5. Bano, M., Lewko, W. M. and Kidwell, W. R. (1984) Characterization of rat mammary tumor cell populations. Cancer Res. 44; 3055-3062.

6. Bates, S. E., Davidson, N. E., Valverius, E. M., Freter, C. E., Dickson, R. B., Tam, J. P., Kudlow, J. E., Lippman, M. E. and Salomon, D. S. (1988) Expression of transforming growth factor alpha and its messenger ribonucleic acid in human breast cancer: its regulation by estrogen and its possible functional significance. Mol. Endocrinol. 2; 543-555.

7. Bogin, L. and Degani, H. (2002) Hormonal regulation of VEGF in orthotopic MCF7 human breast cancer. Cancer Res. 62; 19481951.

8. Boku, N., Yoshida, S., Ohtsu, A., Fujii, T., Koba, I., Oda, Y., Ryu, M., Matsumoto, T., Hasebe, T. and Hosokawa, K. (1995) Expression of integrin alpha 3 in gastric and colorectal cancers: its relation to wall contraction and mode of invasion. Jpn. J. Cancer Res. 86; 934-940.

9. Borg, A., Baldetorp, B., Ferno, M., Killander, D., Olsson, H., Ryden, S. and Sigurdsson, H. (1994) ERBB2 amplification is associated with tamoxifen resistance in steroid-receptor positive breast cancer. Cancer Lett. 81; 137-144.

10. Breier, G., Blum, S., Peli, J., Groot, M., Wild, C., Risau, W. and Reichmann, E. (2002) Transforming growth factor-beta and Ras regulate the VEGF/VEGF-receptor system during tumor angiogenesis. Int. J. Cancer 97; 142-148.

11. Cazzador, L. (1999) Characterization of cell population growth by cell cycle parameters. J. Biotechnol. 71; 245-249.

12. Cheung, S. Y., Yuen, M. T., Choi, H. L., Cheng, H. K., Huang, Y., Chen, S. and Chan, F. L. (2003) An expression study of hormone receptors in spontaneously developed, carcinogen-induced and hormone-induced mammary tumors in female Noble rats. Int. J. Oncol. 22; 1383-1395.

13. Chung, J., Bachelder, R. E., Lipscomb, E. A., Shaw, L. M. and Mercurio, A. M. (2002) Integrin (alpha 6 beta 4) regulation of eIF-4E activity and VEGF translation: a survival mechanism for carcinoma cells. J. Cell Biol. 158; 165-174.

14. Chung, J., Yoon, S., Datta, K., Bachelder, R. E. and Mercurio, A. M. (2004) Hypoxia-induced vascular endothelial growth factor transcription and protection from apoptosis are dependent on alpha6beta1 integrin in breast carcinoma cells. Cancer Res. 64; 4711-4716.

15. Dunnington, D. J., Kim, U., Hughes, C. M., Monaghan, P., Ormerod, E. J. and Rudland, P. S. (1984) Loss of myoepithelial cell characteristics in metastasizing rat mammary tumors relative to their nonmetastasizing counterparts. J. Natl. Cancer Inst. 72; 455-466.

16. Ellis, M. J., Coop, A., Singh, B., Mauriac, L., Llombert-Cussac, A., Janicke, F., Miller, W. R., Evans, D. B., Dugan, M., Brady, C., Quebe-Fehling, E. and Borgs, M. (2001) Letrozole is more effective neoadjuvant endocrine therapy than tamoxifen for ErbB-1- and/or ErbB-2-positive, estrogen receptor-positive primary breast cancer: evidence from a phase III randomized trial. J. Clin. Oncol. 19; 3808-3816.

17. Ferretti, G., Di Cosimo, S., Giannarelli, D., Carlini, P., Papaldo, P., Alimonti, A., Fabi, A., Mandala, M., Milella, M., Ruggeri, E. M. and Cognetti, F. (2004) HER2/neu expression and hormonal therapy in early breast cancer: can muddy waters become clear? J. Clin. Oncol. 22; 568-569.

18. Fujisawa, T., Watanabe, J., Kamata, Y., Hamano, M., Hata, H. and Kuramoto, H. (2003) VEGF expression and its reguration by 
p53 gene transfection in endometrial carcinoma cells. Hum. Cell $16 ; 47-54$.

19. Hanby, A. M., Gillett, C. E., Pignatelli, M. and Stamp, G. W. (1993) Beta 1 and beta 4 integrin expression in methacarn and formalin-fixed material from in situ ductal carcinoma of the breast. J. Pathol. 171; 257-262.

20. Heffelfinger, S. C., Gear, R. B., Taylor, K., Miller, M. A., Schneider, J., LaDow, K. and Warshawsky, D. (2000) DMBAinduced mammary pathologies are angiogenic in vivo and in vitro. Lab. Invest. 80; 485-492.

21. Hoskins, K. and Weber, B. L. (1994) The biology of breast cancer. Curr. Opin. Oncol. 6; 554-559.

22. Huang, R. Y. and Ip, M. M. (2001) Differential expression of integrin mRNAs and proteins during normal rat mammary gland development and in carcinogenesis. Cell Tissue Res. 303; 69-80.

23. Huggins, C., Grand, L. C. and Brillantes, F. P. (1961) Mammary cancer induced by a single feeding of polynuclear hydrocarbons, and its suppression. Nature 189; 204-207.

24. Itoh, J., Yasumura, K., Ogawa, K., Kawai, K., Serizawa, A., Yamamoto, Y. and Osamura, Y. R. (2003) Three-dimensional (3D) imaging of tumor angiogenesis and its inhibition: evaluation of tumor vascular-targeting agent efficacy in the DMBA-induced rat breast cancer model by confocal laser scanning microscopy (CLSM). Acta Histochem. Cytochem. 36; 27-36.

25. Jamieson, S., Dunnington, D. J., Ormerod, E. J., Warburton, M. J. and Rudland, P. S. (1986) Dedifferentiation of rat mammary myoepithelial-like cell lines after passage in vivo or cloning in vitro. J. Natl. Cancer Inst. 76; 247-256.

26. Jensen, E. V. (1991) Steroid hormone receptors. Curr. Top. Pathol. 83; 365-431.

27. Kaidoh, T., Yasugi, T. and Uehara, Y. (1991) The microvasculature of the 7,12-dimethylbenz[a] anthracene (DMBA)-induced rat mammary tumour. Virchows Arch. 418; 111-117.

28. Kang, J. S., Jung, N. J., Kim, S., Kim, D. J., Jang, D. D. and Yang, K. H. (2004) Downregulation of estrogen receptor alpha and beta expression in carcinogen-induced mammary gland tumors of rats. Eksp. Onkol. 26; 31-35.

29. Kiang, D. T. and Kennedy, B. J. (1971) Combination of cyclophosphamide and estrogen therapy in DMBA-induced rat mammary cancer. Cancer 28; 1202-1210.

30. Lee, C. and Oyasu, R. (1974) Direct action of estradiol on rat mammary tumors. J. Natl. Cancer Inst. 52; 283-284.

31. Love, R. R., Duc, N. B., Havighurst, T. C., Mohsin, S. K., Zhang, Q., DeMets, D. L. and Allred, D. C. (2003) Her-2/neu overexpression and response to oophorectomy plus tamoxifen adjuvant therapy in estrogen receptor-positive premenopausal women with operable breast cancer. J. Clin. Oncol. 21; 453-457.

32. Moral, R., Solanas, M., Garcia, G., Colomer, R. and Escrich, E. (2003) Modulation of EGFR and neu expression by $n-6$ and n-9 high-fat diets in experimental mammary adenocarcinomas. Oncol Rep. 10; 1417-1424.

33. Morini, M., Mottolese, M., Ferrari, N., Ghiorzo, F., Buglioni, S., Mortarini, R., Noonan, D. M., Natali, P. G. and Albini, A. (2000) The alpha 3 beta 1 integrin is associated with mammary carcinoma cell metastasis, invasion, and gelatinase B (MMP-9) activity. Int. J. Cancer 87; 336-342.

34. Mukhopadhyay, R., Theriault, R. L. and Price, J. E. (1999) Increased levels of alpha6 integrins are associated with the metastatic phenotype of human breast cancer cells. Clin. Exp. Metastasis 17; 325-332.

35. Nakamura, J., Savinov, A., Qing, L. U. and Brodie, A. (1996) Estrogen regulates vascular endothelial growth/permability factor expression in 7,12-dimethylbenz[a] anthracene-induced rat mammary tumors. Endocrinology 137; 5589-5596.

36. Nass, S. J., Hahm, H. A. and Davidson, N. E. (1998) Breast cancer biology blossoms in the clinic. Nat. Med. 4; 761-762.

37. Nguyen, M., Lee, M. C., Wang, J. L., Tomlinson, J. S., Shao, Z. M., Alpaugh, M. L. and Barsky, S. H. (2000) The human myo- epithelial cell displays a multifaceted anti-angiogenic phenotype. Oncogene 19; 3449-3459.

38. Nicholson, R. I. and Golder, M. P. (1975) The effect of synthetic anti-oestrogens on the growth and biochemistry of rat mammary tumours. Eur. J. Cancer 11; 571-579.

39. O'Neill, P. A., Shaaban, A. M., West, C. R., Dodson, A., Jarvis, C., Moore, P., Davies, M. P., Sibson, D. R. and Foster, C. S. (2004) Increased risk of malignant progression in benign proliferating breast lesions defined by expression of heat shock protein 27. Br. J. Cancer 90; 182-188.

40. Osborne, C. K., Coronado, E. B., Kitten, L. J., Arteaga, C. I., Fuqua, S. A., Ramasharma, K., Marshall, M. and Li, C. H. (1989) Insulin-like growth factor-II (IGF-II): a potential autocrine/paracrine growth factor for human breast cancer acting via the IGF-I receptor. Mol. Endocrinol. 3; 1701-1709.

41. Ruggeri, B. A., Klurfeld, D. M., Kritchevsky, D. and Frick, K. K. (1990) Steady-state mRNA expression for growth factors in DMBA-induced rat mammary tumors. Cancer Lett. 55; 89-93.

42. Ruohora, J. K., Valve, E. M., Karkkainen, M. J., Joukov, V., Alitalo, K. and Harkonen, P. L. (1999) Vascular endothelial growth factors are differentially regulated by steroid hormones and antiestrogens in breast cancer cells. Mol. Cell Endocrinol. 149; 29-40.

43. Russo, J. and Russo, I. H. (2000) Atlas and histologic classification of tumors of the rat mammary gland. J. Mammary Gland Biol. Neoplasia 5; 187-200.

44. Russo, J., Tait, L. and Russo, I. H. (1983) Susceptibility of the mammary gland to carcinogenesis. III. The cell of origin of rat mammary carcinoma. Am. J. Pathol. 113; 50-66.

45. Sherr, C. J. and Roberts, J. M. (1999) CDK inhibitors: positive and negative regulators of G1-phase progression. Genes Dev. 13; 1501-1512.

46. Shimizu, H., Seiki, T., Asada, M., Yoshimatsu, K. and Koyama, N. (2003) Alpha6betal integrin induces proteasome-mediated cleavage of erbB2 in breast cancer cells. Oncogene 22; 831-839.

47. Sjogren, S., Inganas, M., Lindgren, A., Holmberg, L. and Bergh, J. (1998) Prognostic and predictive value of c-erbB-2 overexpression in primary breast cancer, alone and in combination with other prognostic markers. J. Clin. Oncol. 16; 462-469.

48. Tetu, B. and Brisson, J. (1994) Prognostic significance of HER-2/ neu oncoprotein expression in node-positive breast cancer. The influence of the pattern of immunostaining and adjuvant therapy. Cancer 73; 2359-2365.

49. Torimura, T., Ueno, T., Kin, M., Ogata, R., Inuzuka, S., Sugawara, H., Kurotatsu, R., Shimada, M., Yano, H., Kojiro, M., Tanikawa, K. and Sata, M. (1999) Integrin alpha6beta1 plays a significant role in the attachment of hepatoma cells to laminin. J. Hepatol. 31; 734-740.

50. Varner, J. A. and Cheresh, D. A. (1996) Integrins and cancer. Curr. Opin. Cell Biol. 8; 724-730.

51. Von Marschall, Z., Cramer, T., Hocker, M., Finkenzeller, G., Wiedenmann, B. and Rosewicz, S. (2001) Dual mechanism of vascular endothelial growth factor upregulation by hypoxia in human hepatocellular carcinoma. Gut 48; 87-96.

52. Wirl, G., Kronberger, A. and Langanger, G. (1984) Epithelial organoids and mononuclear phagocytes from DMBA-induced mammary tumors of the rat secrete collagenase in vitro. Exp. Cell Res. 151; 502-518.

53. Yoshida, H., Yoshida, A., Fukunishi, R., Nagato, T. and Uehara, Y. (1980) Scanning electron microscopy of 7,12-dimethylbenz(a)-anthracene-induced mammary carcinoma in the female Sprague-Dawley rat. Virchows Arch. B Cell Pathol. 32; 105-108.

54. Zhou, S., Schuetz, J. D., Bunting, K. D., Colapietro, A. M., Sampath, J., Morris, J. J., Lagutina, I., Grosveld, G. C., Osawa, M., Nakauchi, H. and Sorrentino, B. P. (2001) The ABC transporter Bcrp1/ABCG2 is expressed in a wide variety of stem cells and is a molecular determinant of the side-population phenotype. Nat. Med. 7; 1028-1034. 